Research Article

\title{
Managing a Dual-Channel Supply Chain with Fairness and Channel Preference
}

\author{
Xianjin Du ${ }^{1}{ }^{1}$ and Weijie Zhao ${ }^{1,2}$ \\ ${ }^{1}$ School of Management, Hefei University of Technology, Hefei 230009, China \\ ${ }^{2}$ Huishang Bank, Hefei 230009, China \\ Correspondence should be addressed to Xianjin Du; xianjindu@hfut.edu.cn
}

Received 17 November 2020; Revised 8 December 2020; Accepted 24 December 2020; Published 8 January 2021

Academic Editor: Fateh Mebarek-Oudina

Copyright ( 2021 Xianjin Du and Weijie Zhao. This is an open access article distributed under the Creative Commons Attribution License, which permits unrestricted use, distribution, and reproduction in any medium, provided the original work is properly cited.

\begin{abstract}
This paper investigates a dual-channel supply chain in which a manufacturer sells the product via an offline retailer or online store. The manufacturer sets the wholesale and online price, and the retailer decides the retail price with the retailer's fairness preference and consumer's online channel preference. Through investigating the combined impacts of fairness preference and channel preference on the enterprises' operational strategies, this paper obtains some meaningful results. If a manufacturer thinks over the fairness preference, he decreases the wholesale price to mitigate a loss of retailer and benefit the supply chain design. The manufacturer intends to set up the online channel with a lower acceptance as the fairness preference grows. However, the gains from enhanced online channel acceptance cannot compensate for the manufacturer's loss by the fairness effect that benefits the retailer. Moreover, the manufacturer cannot neglect the retailer's fairness preference generating a "lose-lose" case for both members.
\end{abstract}

\section{Introduction}

With the increasing innovation of information technology and vigorous publicity by commercial organizations, consumers are getting used to online shopping. According to China Statistical Yearbook-2020, online sales in China reached 155.2 billion dollars in 2019, increasing $16.5 \%$ over the previous year (https://www.chinainternetwatch.com/ $30232 /$ retail\%202019/). To seize the Internet opportunity, many enterprises have set up the supply chain composed of online and offline channels such as Apple, Nike, Zara, and Huawei, and many scholars study dual-channel supply chain under different cases. A few papers focus on how the consumer's online channel preference impacts the dualchannel strategy (Chiang et al. [1], Xu et al. [2], and Zhang et al. [3]), while others try to find the operational strategy for the dual-channel supply chain (Guo et al. [4] and Zhu et al. [5]). There is also a lot of research (Chen et al. [6], Cui et al. [7], Guan et al. [8], Niu et al. [9], and Pan et al. [10]) studying the impact of fairness preference in the supply chain, especially the supply chain design decisions and coordination. However, the combined effect of the retailer's fairness and consumer's online channel preference is ignored in the dualchannel design, which motivates our research. To fill this gap, our paper considers a dual-channel system in which the retailer has fairness preference, and the consumers are differentiated in online channel acceptance. The primary purposes of our research are to address the following issues:

(1) Varying with consumer's online channel preference and fairness concern, how do the manufacturer and retailer decide their operational strategy, including pricing and dual-channel design? Also, how do the related parameters affect the manufacturer's and retailer's strategy?

(2) With the increases in the consumer's online channel preference, can the manufacturer's profit be better when the retailer has a fairness preference? 
(3) Can the manufacturer ignore the retailer's fairness preference? What strategy would be adopted by the retailer if the manufacturer ignores it?

To tackle these issues, the paper establishes a dualchannel decision model composed of a manufacturer (he) and a retailer (she). The model has three circumstances: the retailer without fairness preference, the manufacturer considering her fairness preference, and ignoring her fairness preference. The paper studies the synergistic impact of consumer online channel acceptance and retailer's fairness preference on members' pricing decisions and profits. It compares and analyzes optimal decisions under the above three circumstances. Different from other literatures that independently examine the influence of supply chain enterprises' decisions from the perspective of consumer's online channel preference or retailers' fairness, this paper obtains some meaningful conclusions as follows: (i) If a manufacturer thinks over the fairness preference, he decreases his wholesale price to mitigate a loss of retailer. The increase in consumer online channel acceptance would strengthen the trend. However, the manufacturer also intends to build an online channel with a lower consumer online channel acceptance to decrease his dependence on the retailer. (ii) Whether the manufacturer considers or ignores fairness preference, the increase of consumer online channel acceptance cannot compensate for the manufacturer's loss due to the retailer's fairness effect. The manufacturer's interest concessions via wholesale price reduction caused by the consideration of the retailer's fairness preference exceed the benefit from the increase of online shopping. (iii) If the manufacturer overlooks the retailer's fairness, they will fall into a "lose-lose" case. The retailer would price higher to make up for the online market's loss, which also injures her profit. This also brings harm to the sale resulting in the reduction of the manufacturer's profit.

The rest of the paper is arranged as follows. Section 2 is a review of relevant literature with two streams. Section 3 establishes a game model with one leading manufacturer and one following retailer. It examines the members' pricing decisions and profits when the retailer has no fairness preference as a benchmark case. Section 4 consists of two situations as comparative cases, where the manufacturer considers or ignores the retailer's fairness preference. The enterprises' decisions and profits in two different situations are obtained. Section 5 analyzes the manufacturer's decisions on setting up the online channel under different scenarios. Section 6 makes some comparisons between different situations. Section 7 concludes the paper.

\section{Literature Review}

This paper is related to two literature streams: the online channel preference and the retailer's fairness preference in the supply chain.

The first related stream of the literature focuses on the online channel preference that includes Zhang et al. [3], Guo et al. [4], Zhu et al. [5], Cai [11], Cao [12], Dumrongsiri et al. [13], Dan et al. [14], Gao et al. [15], Hua et al. [16], Huang and Swaminathan [17], Li et al. [18], Lu and Liu [19], Ranjan and Jha [20], and Yoo and Lee [21]. For instance, Zhang et al. [3] find that the channel selections are determined by the consumer's online acceptance. Guo et al. [4] show that the dual channel may make traditional retailers feel threatened. Dumrongsiri et al. [13] show that the uncertain demand obviously affects the optimal pricing and the manufacturer's incentive to seek an online channel. Hua et al. [16] demonstrate that consumer acceptance of online purchases can positively affect the manufacturer's online pricing and lead to longer delivery lead times. Li et al. [18] find that, with the high consumer's online acceptance, the manufacturer provides customized products under the decentralized and centralized supply chain structures. Gao et al. [15] and Lu and Liu [19] investigate how the consumer's online acceptance affects the dual-channel excepted profits and obtain that the consumer's online acceptances positively affect the manufacturer's profit, while the retailer's gain is the opposite. Ranjan and Jha [20] think over the effect of retailers' risk attitude and demand uncertainty on the pricing mechanism among dual-channel members.

The second related stream of the literature concentrates on fairness preference in supply chain management including Chen et al. [6], Cui et al. [7], Guan et al. [8], Niu et al. [9], Caliskan-Demirag et al. [22], Du et al. [23], Ho et al. [24], Katok and Pavlov [25], Q. H. Li and B. Li [26], Nie and Du [27], and Du et al. [28]. Cui et al. [7] introduce members' fairness preference into the dyadic supply chain and conclude that the channel can be coordinated by using a wholesale price contract. Guan et al. [8] extend the analysis of the impact of peer-fairness or Nash bargaining fairness preference on the pricing of supply chain enterprises and the overall efficiency of the supply chain. Niu et al. [9] study the role of channel strength and fairness preference in online channel opening and find that supplier fairness concerns are not conducive to online channel development. Chen et al. [6] and Pan et al. [10] show that the enhancement of the retailer's rights will make her pay attention to the fairness of her own profits, which may improve the supply chain's performance. Caliskan-Demirag et al. [22] research channel coordination issues with different fairness concerns through a simple wholesale price and other nonlinear demands. Du et al. [23] analyze the impact of fairness preference behavior on enterprise decisions and channel efficiency and show that although channel efficiency will be reduced, fairness preference still coordinates the supply chain in specific cases. Q. H. Li and B. Li [26] study the channel issues with retailer's fairness preference and show the fairness concern's negative impacts on channel efficiency.

The above literature studies the influence of supply chain members' decision-making in the sense of consumer's online channel preference or retailers' fairness. Unlike the related research, our paper first studies the combining effect of both consumer's online channel preference differences and the retailer's fairness preference on supply chain decisions. Therefore, our paper theoretically enriches the supply chain design research, which is more practical. It helps decision-makers be aware of the critical role of fairness preference behavior and online consumer heterogeneity in 
decision-making. Moreover, our research allows decisionmakers to use these factors to reach supply chain efficiency improvement and provide guidance for the enterprises.

\section{Benchmark Model}

3.1. Model Description. This paper develops a dual-channel supply chain, including one manufacturer (he) and one retailer (she). There is a Stackelberg game between the manufacturer and the retailer, with the manufacturer dominating the supply chain and the retailer being the follower. The manufacturer wholesales the product at the wholesale price $w$ to the retailer, with the cost $c$, while the retailer sells it to consumers at a retail price $p_{r}$. With the popularity of online shopping, the manufacturer opens up an online channel to increase market penetration with online price $p_{e}$ and gain more profits. In turn, the manufacturer has a dual-channel structure, consisting of an offline channel and an online channel as shown in Figure 1.

The demand function refers to the analyses of Chiang et al. [1], Dan et al. [14], and Huang and Swaminathan [17]. The manufacturer's online channel demand function $q_{e}$ and the retailer's offline channel demand function $q_{r}$ are as follows:

$$
\begin{aligned}
& q_{e}=\theta a-b p_{e}+\lambda p_{r}, \\
& q_{r}=(1-\theta) a-b p_{r}+\lambda p_{e},
\end{aligned}
$$

where $a$ indicates the basic demand of the market. $\theta(0<\theta<1)$ measures the consumer's online channel preference and $1-\theta$ indicates the consumer's offline channel acceptance. $b$ denotes the influence factor of the channel price on demand, while $\lambda$ denotes the influence factor of the cross-price with $b>\lambda$.

The manufacturer's rationality means that the maximization of its profit is the decision-making process's decision-making goal. The fairness preference of a retailer indicates that the retailer is concerned with maximizing its utility when making decisions. The retailer's fairness preference model draws on the FS model [29], and its utility function is the following:

$$
U_{r}=\prod_{r}-\alpha \max \left(\prod_{m}-\prod_{r}, 0\right)-\beta \max \left(\prod_{r}-\prod_{m}, 0\right) .
$$

The coefficients of $\alpha$ and $\beta$ are the disadvantage and advantage inequity aversion, respectively. Qin and Yang [30] show that, in the Stackelberg game of the two-tier supply chain, the member playing the leadership role can reap more than half of the overall profits. Thus, in this study, only the disadvantage inequity averseness of the retailer is considered. The retailer's utility function is as follows:

$$
U_{r}=\prod_{r}-\alpha \max \left(\prod_{m}-\prod_{r}, 0\right) .
$$

The relevant symbols are shown in Table 1.

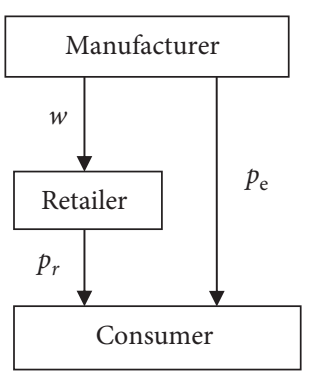

FIgURE 1: The dual-channel supply chain.

TABle 1: Nomenclature.

\begin{tabular}{lc}
\hline Notation & Definition \\
\hline$\Pi_{m}$ & Manufacturer's profit \\
$\Pi_{r}$ & Retailer's profit \\
$U_{m}$ & Manufacturer's utility \\
$U_{r}$ & Retailer's utility \\
$w$ & Wholesale price \\
$p_{e}$ & Online channel price \\
$p_{r}$ & Offline channel price \\
$c$ & Manufacturer's cost \\
$\theta$ & Consumer's online channel preference \\
$a$ & Total market demand \\
$b$ & Price elasticity \\
$\lambda$ & Cross-price elasticity \\
$\alpha$ & Coefficient of retailer fairness preference \\
\hline
\end{tabular}

3.2. The Retailer without Fairness Preference. In this context, the profits functions of the manufacturer and the retailer are as follows:

$$
\begin{aligned}
& \prod_{m}=(w-c) q_{r}+\left(p_{e}-c\right) q_{e}, \\
& \prod_{r}=\left(p_{r}-w\right) q_{r},
\end{aligned}
$$

and, with backward induction to solve this problem, it can be easily verified that when the retailer has no fairness preference, the equilibrium pricing strategies and profits for the manufacturer and the retailer are

$$
\begin{aligned}
& p_{e}=\frac{(\lambda+b \theta-\lambda \theta) a+\left(b^{2}-\lambda^{2}\right) c}{2\left(b^{2}-\lambda^{2}\right)} \\
& w=\frac{(b+\lambda \theta-b \theta) a+\left(b^{2}-\lambda^{2}\right) c}{2\left(b^{2}-\lambda^{2}\right)} \\
& p_{r}=\frac{\left[3 b^{2}(1-\theta)+\lambda \theta(2 b+\lambda)-\lambda^{2}\right] a+c(b-\lambda)(b+\lambda)^{2}}{4 b\left(b^{2}-\lambda^{2}\right)} .
\end{aligned}
$$

According to the above optimal pricing decisions, the optimal profits for the retailer and the manufacturer without fairness preference are 


$$
\begin{aligned}
& \prod_{r}=\frac{[a(\theta-1)+c(b-\lambda)]^{2}}{16 b}, \\
& \prod_{m}=\frac{a^{2} A_{1}-2 a c\left(b^{2}-\lambda^{2}\right) A_{2}+c^{2}(b-\lambda)^{2} A_{3}}{8 b\left(b^{2}-\lambda^{2}\right)},
\end{aligned}
$$

where $A_{1}=\left(3 b^{2}+\lambda^{2}\right) \theta^{2}-4 b \lambda \theta(\theta-1)+(1-2 \theta)\left(b^{2}+\lambda^{2}\right)$, $A_{2}=\theta(b-\lambda)+(b+\lambda)$, and $A_{3}=3 b^{2}+\lambda^{2}+4 b \lambda$.

\section{The Model with the Retailer's Fairness Preference}

There are two circumstances when the retailer has a fairness preference. One case is when the manufacturer considers the retailer's fairness preference and the other is when the manufacturer ignores it. The paper analyzes the different cases with Sections 4.1 and 4.2. The subscript ${ }^{*}$ represents the manufacturer's optimal decisions considering the retailer's fairness preference; the subscript ${ }^{* *}$ means the optimal choices with the manufacturer ignoring the retailer's fairness preference.

4.1. The Manufacturer Considers the Retailer's Fairness Preference. In this situation, the utility functions of the manufacturer and the retailer are

$$
\begin{aligned}
& U_{m}=\prod_{m}, \\
& U_{r}=\prod_{r}-\alpha\left(\prod_{m}-\prod_{r}\right)=(1+\alpha) \prod_{r}-\alpha \prod_{m} .
\end{aligned}
$$

Lemma 1. When the manufacturer considers the retailer's fairness preference, the equilibrium pricing strategies and profits for the manufacturer and the retailer are

$$
\begin{aligned}
& p_{e}^{*}=\frac{(\lambda+b \theta-\lambda \theta) a+\left(b^{2}-\lambda^{2}\right) c}{2\left(b^{2}-\lambda^{2}\right)}, \\
& w^{*}=\frac{(3 \alpha c+c) b^{3}-((c \lambda+(\theta-1) a) \alpha+(\theta-1) a) b^{2}+\left(\left(2 a \lambda \theta-3 c \lambda^{2}\right) \alpha+a \lambda \theta-c \lambda^{2}\right) b-(-\lambda c+(\theta-1) a) \lambda^{2} \alpha}{2 b\left(b^{2}-\lambda^{2}\right)(1+2 \alpha)}, \\
& p_{r}^{*}=\frac{\left[3 b^{2}(1-\theta)+\lambda \theta(2 b+\lambda)-\lambda^{2}\right] a+c(b-\lambda)(b+\lambda)^{2}}{4 b\left(b^{2}-\lambda^{2}\right)} .
\end{aligned}
$$

According to the above optimal pricing, it can be obtained that $\prod_{r}$ and $\prod_{m}$ in this case are

$$
\begin{aligned}
& \prod_{r}^{*}=\frac{[a(\theta-1)+c(b-\lambda)]^{2}(4 \alpha+1)}{16 b(2 \alpha+1)}, \\
& \prod_{m}^{*}=\frac{a^{2} B_{1}-2 a c\left(b^{2}-\lambda^{2}\right) B_{2}+c^{2}(b-\lambda)^{2} B_{3}}{8 \mathrm{~b}\left(b^{2}-\lambda^{2}\right)(2 \alpha+1)},
\end{aligned}
$$

where $\quad B_{1}=\left[(5 \alpha+3) \theta^{2}+(1+\alpha)(1-2 \theta)\right] b^{2}+(3 \alpha+1)$ $(\theta-1)^{2}+4 b \lambda(1-\theta)(1+2 \alpha), \quad B_{2}=3 \alpha \theta(b-\lambda)+b(\alpha+\theta)$ $+\lambda(3 \alpha-\theta)+b+\lambda$, and $B_{3}=(5 \alpha+3) b^{2}+(3 \alpha+1) \lambda^{2}+4 b \lambda$ $(2 \alpha+1)$.

Proof of Lemma 1. Solving the Stackelberg game, the backward induction is used as follows.

Inserting (6) and (12) into (13) produces

$$
\begin{aligned}
U_{r}= & (1+\alpha)\left(p_{r}-w\right)\left((1-\theta) a-b p_{r}+\lambda p_{e}\right) \\
& -\alpha(w-c)\left((1-\theta) a-b p_{r}+\lambda p_{e}\right) \\
& -\alpha\left(p_{e}-c\right)\left(\theta a-b p_{e}+\lambda p_{r}\right) .
\end{aligned}
$$

As $\left(\partial U_{r} / \partial p_{r}\right)=0$ and $\left(\partial^{2} U_{r} / \partial p_{r}^{2}\right)=-2 b(1+\alpha)<0$, the retailer has the only optimal retail price. The first-order partial derivative of $U_{r}$ concerning $p_{r}$ is expressed as follows:

$$
p_{r}\left(w, p_{e}\right)=\frac{[a(1-\theta)-c(b+\lambda)+2 b w] \alpha+a(1-\theta)+b w-\lambda p_{e}}{2 b(1+\alpha)} .
$$

To verify that $\prod_{m}$ is a joint concave function on wholesale price $w$ and online price $p_{e}$, the second-order conditions can be obtained:

$$
\left\{\begin{array}{l}
\frac{\partial^{2} \prod_{m}}{\partial w^{2}}=\frac{-b(1+2 \alpha)}{1+\alpha}<0 \\
\frac{\partial^{2} \prod_{m}}{\partial p_{e}^{2}}=\frac{\lambda^{2}}{(1+\alpha) b}-2 b<0 \\
\frac{\partial^{2} \prod_{m}}{\partial w \partial p_{e}}=\frac{(1+2 \alpha) \lambda}{1+\alpha}>0 .
\end{array}\right.
$$


As the Hessian matrix of the $\prod_{m}$ above formulae is negative, it has a unique optimal solution. Then setting $\left(\delta \Pi_{m} / \delta w\right)$ and $\left(\delta \Pi_{m} / \delta p_{e}\right)$ to zero yields

$$
\left\{\begin{array}{l}
w=\frac{\left[a(1-\theta)+3 b c-3 c \lambda+4 \lambda p_{e}\right] \alpha+a(1-\theta)+b c-c \lambda+2 \lambda p_{e}}{2 b(1+2 \alpha)}, \\
p_{e}=\frac{\left(2 a b \theta-a \lambda \theta+2 b^{2} c-3 b c \lambda+4 b w \lambda+c \lambda^{2}+a \lambda\right) \alpha+2 a b \theta-a \lambda \theta+2 b^{2} c-b c \lambda+2 b w \lambda-c \lambda^{2}+a \lambda}{2\left(2 b^{2} \alpha+2 b^{2}-\lambda^{2}\right)} .
\end{array}\right.
$$

Solving (20) and (22) can obtain the optimal pricing as (14)-(16). Then inserting (14)-(16) into (5) and (6) produces the equilibrium profits for the retailer and the manufacturer as (17) and (18). Lemma 1 is proved.

4.2. The Manufacturer Ignores the Retailer's Fairness Preference. In this subsection, the paper assumes that the retailer's fairness preference information is not taken into account by the manufacturer. Under this condition, the manufacturer still prices considering that the retailer has no fairness preference, which is represented by $w^{* *}=w$ and $p_{e}^{* *}=p_{e}$. However, the retailer has a fairness preference and uses the utility function of equation (13) to make optimal decisions.

Lemma 2. When the manufacturer ignores the retailer's fairness preference, the offline price and the manufacturer's and retailer's profits are

$$
p_{r}^{* *}=\frac{\left(2 a b \lambda \theta-4 a b^{2} \theta+2 a \lambda^{2} \theta+2 b^{2} c \lambda-2 c \lambda^{3}+4 a b^{2}-2 a \lambda^{2}\right) \alpha+\left[3 b^{2}(1-\theta)+\lambda \theta(2 b+\lambda)-\lambda^{2}\right] a+c(b-\lambda)(b+\lambda)^{2}}{4 b(1+\alpha)\left(b^{2}-\lambda^{2}\right)}
$$

$\prod_{r}$ and $\prod_{m}$ can be calculated as

$$
\begin{aligned}
& \prod_{r}^{* *}=\frac{[a(\theta-1)+c(b-\lambda)]^{2}(1+2 \alpha)}{16 b(1+\alpha)^{2}}, \\
& \prod_{m}^{* *}=\frac{a^{2} C_{1}-2 a c\left(b^{2}-\lambda^{2}\right) C_{2}+c^{2}(b-\lambda)^{2} C_{3}}{8 b\left(b^{2}-\lambda^{2}\right)(1+\alpha)},
\end{aligned}
$$

where $C_{1}=(2 \alpha+3) b^{2} \theta^{2}-4 b \lambda \theta(\theta-1)(1+\alpha)+\left[2 \alpha(\theta-1)^{2}\right.$ $\left.+\theta^{2}\right] \lambda^{2}+(1-2 \theta)\left(b^{2}+\lambda^{2}\right), \quad C_{2}=\theta(b-\lambda)(2 \alpha+1)+2 \alpha \lambda b$ $+b+\lambda$, and $C_{3}=[(b+\lambda) \alpha+2 b](b+\lambda)$.

Following the calculating process of the proof of Lemma 1 in Section 4.1, Lemma 2 can be easily proved. The detailed formulae are not provided here.

\section{Supply Chain Design Analysis}

This section analyzes the manufacturer's decisions on setting up the online channel under different scenarios. When the manufacturer ignores the fairness concern of the retailer, his strategy is the same as the retailer who has no fairness preference shown in Section 4.2. Therefore, the two possible situations are as follows.

5.1. The Retailer without Fairness Preference. As the manufacturer's online price is greater than the wholesale price $\left(p_{e}>w\right)$, this results in $\theta>(1 / 2)$. If $0<\theta<(1 / 2)$, then $p_{e}<w$. The retailer can purchase large quantities of goods from the online channel and then sell them offline to make more profits, contrary to the manufacturer's original intention to set up an online channel.

Moreover, the retailer's offline channel's price should be greater than the manufacturer's wholesale price, which means that $p_{r}>w$ and results in $\theta<((a-c(b-\lambda)) / a)$. If $((a-c(b-\lambda)) / a)<\theta<1$, then $p_{r}<w$. It will bring loss to the retailer and cause the retailer to abandon the offline channel. The dual-channel supply chain may need to be reconstructed if $\theta$ is out of $((1 / 2),((a-c(b-\lambda)) / a))$.

Following the same analytical process above, this paper could find that the range is as same as that when the manufacturer ignores the fairness concern of the retailer. The paper concludes the supply chain design strategy in Lemma 3 as follows.

Lemma 3. If the retailer does not have fairness preference or the manufacturer ignores her preference, the manufacturer intends to build an online channel when $\theta>(1 / 2)$. When $\theta$ approaches $((a-c(b-\lambda)) / a)$, the retailer may choose to quit the supply chain.

Lemma 3 indicates that when the retailer has no fairness preference or the manufacturer ignores it, the manufacturer 
chooses to develop an online channel when the consumers are more receptive to them. Furthermore, the retailer is unwilling to participate in the dual-channel operation if the online channel acceptance exceeds a threshold. For the manufacturer, if he continues to use the dual channel to protect market penetration, he may need to provide additional benefits for the retailer.

5.2. The Manufacturer Considers the Retailer's Fairness Preference. Now this paper discusses the supply chain design strategy when the retailer possesses the fairness preference. Following the analytic process in Section 5.1, it can get $\theta>\left(\left(\alpha c\left(b^{2}-\lambda^{2}\right)+\alpha a(b-\lambda)+a b\right) /(a(3 b \alpha-\alpha \lambda+2 b))\right)$ as $p_{e}^{*}>w^{*}$. With $p_{r}^{*}>w^{*}$, it gets $\theta<((a-c(b-\lambda)) / a)$. When the lower bound $\left(\left(\alpha c\left(b^{2}-\lambda^{2}\right)+\alpha a(b-\lambda)\right.\right.$ $+a b) /(a(3 b \alpha-\alpha \lambda+2 b)))$ is used to get the derivation of $\alpha$, $\left((b(b+\lambda)[2 c(b-\lambda)-a]) /\left(a(3 b \alpha-\alpha \lambda+2 b)^{2}\right)\right)<0$ can be obtained. This shows that the manufacturer intends to develop a new road to market as he decreases the wholesale price for the retailer's fairness concerns. The upper bound of $\theta$ remains unchanged because the high consumer's online channel preference may lead to the suspension of the retailer's sales. So, the upper bound of $\theta$ is not affected by fairness preference.

Lemma 4 shows the manufacturer's supply chain design strategy when considering the retailer's fairness preference.

Lemma 4. When the manufacturer takes the retailer's fairness into account, the dual-channel supply chain works if and only if $\left(\left(\alpha c\left(b^{2}-\lambda^{2}\right)+\alpha a(b-\lambda)+a b\right) /(a(3 b \alpha-\alpha \lambda+\right.$ $2 b)))<\theta<((a-c(b-\lambda)) / a)$. With the increase of the fairness preference coefficient, the lower bound of $\theta$ will gradually decrease.

Intuitively, if the retailer focuses on fairness, the manufacturer will transfer some profit to the retailer to eliminate its fairness. However, the manufacturer also wants to offset the offline supply chain's loss by adding an online channel. This brings a decrease in the starting point of opening an online channel. As the acceptance is low, the retailer does not think that the online channel is a threat, and the manufacturer can also get a little profit by adding an online channel. Lemma 4 shows that if a retailer pursues the fairness of her profit excessively, the manufacturer becomes urgent for setting up an online channel, even though consumers have a low preference for an online channel. However, this is not beneficial for the retailer, which means that she should maintain an appropriate level of fairness.

\section{Comparative Analysis}

Given the strategies under the three circumstances mentioned in Section 3 and 4, this paper compares operational strategies between the manufacturer and the retailer to analyze the effects of the retailer's fairness preference and consumer's online channel preference.

\subsection{Pricing Comparison}

Lemma 5. For pricing strategies,

(a) $p_{e}=p_{e}^{*}=p_{e}^{* *}, w^{*}<w=w^{* *}$, and $p_{r}=p_{r}^{*}<p_{r}^{* *}$;

(b) $\left(\partial w^{*} / \partial \alpha\right)<0, \quad\left(\partial w^{*} / \partial \theta\right)<0, \quad\left(\partial p_{r}^{* *} / \partial \alpha\right)>0$, and $\left(\partial p_{r}^{* *} / \partial \theta\right)<0$.

Proof of Lemma 5. When the manufacturer considers the retailers' fairness preference, $w^{*}-w<0 ; \quad\left(\partial w^{*} / \partial \alpha\right)=$ $\left((a(\theta-1)+c(b-\lambda)) /\left(2 b(1+2 \alpha)^{2}\right)\right)$ and $\left(\partial w^{*} / \partial \theta\right)=$ $-((a[\alpha(b-\lambda)+b]) /(2 b(b+\lambda)(1+2 \alpha)))<0$ can be obtained when formula (15) is used to get the derivations of $\alpha$ and $\theta .\left(\partial w^{*} / \partial \alpha\right)=\left((a(\theta-1)+c(b-\lambda)) /\left(2 b(1+2 \alpha)^{2}\right)\right)<0$ because $\theta<((a-c(b-\lambda)) / a)$ is demonstrated in Lemmas 3 and 4 . When the manufacturer ignores the retailer's fairness preference, $\quad p_{r}^{* *}-p_{r}>0 . \quad\left(\partial p_{r}^{* *} / \partial \alpha\right)=((a(1-\theta)-$ $\left.c(b-\lambda)) /\left(4 b(1+\alpha)^{2}\right)\right)>0$ and $\left(\partial p^{* *} / \partial \theta\right)=-((a[b(4 \alpha+$ $3)+\lambda(2 \alpha+1)]) /(4 b(b+\lambda)(1+\alpha)))<0$ can be obtained when formula (23) is used to get the derivation of $\alpha$.

It can be seen from Lemma 5 that when the manufacturer thinks over the retailer's fairness preference, the wholesale price reduces as the fairness preference coefficient increases. If the manufacturer ignores it, the retail price improves with the fairness preference coefficient increasing. Moreover, taking the rise in consumers' online channel preferences into account, the wholesale will decline faster, but the retail price growth slows down. To demonstrate the impact of the fairness preference coefficient on supply chain members' pricing decisions and profits in Lemma 5 more clearly, this paper numerically analyzes the above model and discusses the results. The numerical results are shown in Figures 2 and 3 with $a=100, b=1, \lambda=0.4, c=10$. The parameter values are also applicable to subsequent numerical legends. As shown in Figure 2, it can be seen directly that when $\theta$ is constant, with the increase of $\alpha, w^{*}$ continues to fall. In order to make the dual channels work, the value of $\theta$ should be greater than $1 /$ 2. Moreover, when $\alpha$ is constant, the wholesale price still deceases with the increase of $\theta$. According to Figure 3 , when $\theta$ is constant, with the increase of $\alpha$, the retail price improves when the manufacturer ignores the retailer's fairness preference. If $\alpha$ is constant, the retail price decreases with the increase of $\theta$.

When the manufacturer takes the retailer's fairness preference into account, he lowers the wholesale price to maintain the balance of channel profit distribution. When the increase in consumer's online channel preference weakens the retailer's market competitiveness, consumers are willing to choose shopping online. To compensate for the loss of the retailer, the manufacturer's wholesale price will fall more. Moreover, because the manufacturer ignores the retailer's fairness preference, with the fairness preference increase, the retailer's focus on fairness will force her to raise pricing for the sake of maintaining profits. However, with the increase of consumer's online preference, the retailer chooses to reduce the retail price attracting consumers to select the offline channel. 


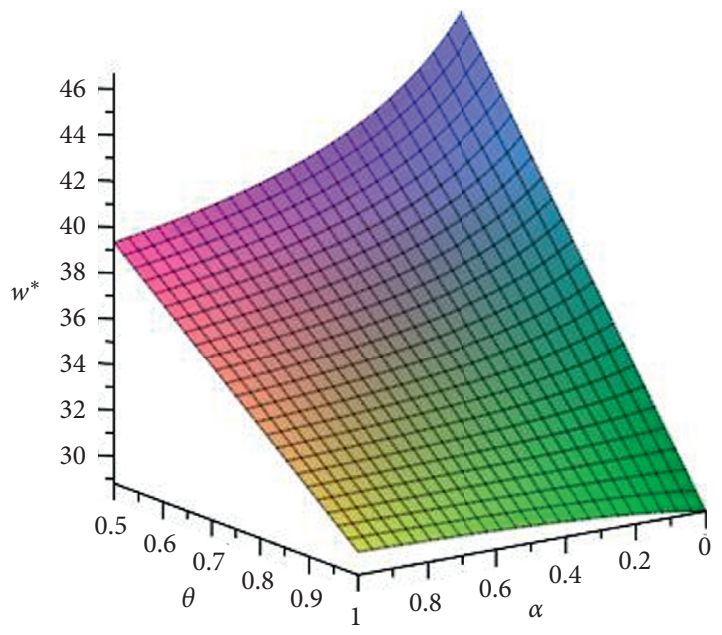

FIGURE 2: The influence of $\alpha$ and $\theta$ on $w^{*}$.

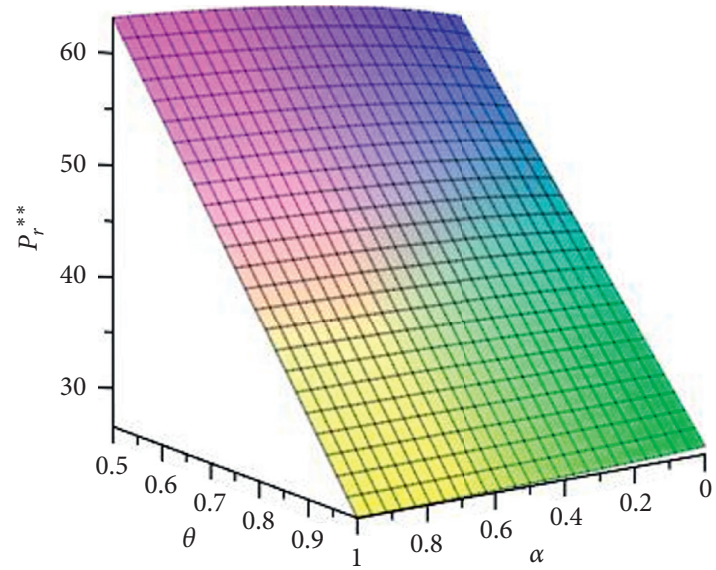

FIgURE 3: The influence of $\alpha$ and $\theta$ on $p_{r}^{* *}$.

\subsection{The Retailer's Profits Comparison}

Lemma 6. For the retailer's profits under the above three circumstances,

(a) $\prod_{r}^{*}>\prod_{r}>\prod_{r}^{* *}$

(b) $\left(\partial \prod_{r}^{*} / \partial \alpha\right)>0,\left(\partial \prod_{r}^{*} / \partial \theta\right)<0,\left(\partial \prod_{r}^{* *} / \partial \alpha\right)<0$, and $\left(\partial \prod_{r}^{* *} / \partial \theta\right)<0$

Proof of Lemma 6. It can be easily calculated from (10), (17), and (24) that $\prod_{r}^{*}-\prod_{r}>0$ and $\prod_{r}-\prod_{r}^{* *}>0 .\left(\partial \prod_{r}^{*} / \partial \alpha\right)=$ $\left(\left([a(\theta-1)+c(b-\lambda)]^{2}\right) /\left(8 b(2 \alpha+1)^{2}\right)\right)>0$ and $\left(\partial \prod_{r}^{*} /\right.$ $\partial \theta)=((a(4 \alpha+1)[a(\theta-1)+c(b-\lambda)]) /(8 b \quad(1+2 \alpha)))<0$ can be obtained when (17) is used to get the derivation of $\alpha$ and $\theta .\left(\partial \prod_{r}^{* *} / \partial \alpha\right)=\left(\left(-\alpha[a(\theta-1)+c(b-\lambda)]^{2}\right) /(8 b(1+\right.$ $\left.\left.\alpha)^{3}\right)\right)<0$ and $\left(\partial \prod_{r}^{* *} / \partial \theta\right)=((a(2 \alpha+1)[a(\theta-1)+c(b-$ $\left.\lambda)]) /\left(8 b(1+2 \alpha)^{2}\right)\right)<0$ can be obtained when (24) is used to get the derivation of $\alpha$ and $\theta$.

Lemma 6 shows that the retailer can increase profitability when she focuses on fairness. The manufacturer considers the retailer's fairness preference, which enhances the retailer's bargaining power. He transfers profits to the retailer in various ways, consistent with the recent literature, such as Caliskan-Demirag et al. [22] and Ho et al. [24]. However, it is obvious that the retailer's profit with the manufacturer considering the retailer's fairness preference improves when the consumer's online acceptance increases. If the manufacturer ignores her fairness preference, the retailer intends to increase profits by increasing her pricing demonstrated in Lemma 5. But this reduces the retailer's sales and results in a decrease in the retailer's profit. Moreover, the retailer's profit decreases faster as the consumer's online channel preference increases. It is easy to understand that the number of consumers choosing to shop offline reduces while the online channel acceptance increases. This decrease in retailer sales leads to a decline in profits if the manufacturer ignores the retailer's fairness preference and does not transfer the earning.

The numerical analysis also shows the above results more intuitively. From Figure 4, if $\theta$ is at a certain value, with the increase of $\alpha$, the retailer's profit with the manufacturer considering her fairness preference improves. However, if $\alpha$ is at a certain value, the retailer's profit decreases with the increase of $\theta$. Similarly, it is obvious from Figure 5 that when $\theta$ is at a certain value, with the increase of $\alpha$, the retailer's profit with the manufacturer ignoring the retailer's fairness preference reduces. If $\alpha$ is at a certain value, the retailer's profit also decreases with the increase of $\theta$.

\subsection{The Manufacturer's Profits Comparison}

Lemma 7. For the above three circumstances,

(a) $\prod_{m}>\prod_{m}^{*}>\prod_{m}^{* *}$;

(b) $\left(\partial \prod_{m}^{*} / \partial \alpha\right)<0, \quad\left(\partial \prod_{m}^{*} / \partial \theta\right)>0, \quad\left(\partial \prod_{m}^{* *} / \partial \alpha\right)<0$, and $\left(\partial \prod_{m}^{* *} / \partial \theta\right)>0$.

Proof of Lemma 7. With formulae (11), (18), and (25), $\prod_{m}-$ $\prod_{m}^{*}>0$ and $\prod_{m}^{*}-\prod_{m}^{* *}>0$ are got. $\left(\partial \prod_{m}^{*} / \partial \alpha\right)=$ $-\left(\left([a(\theta-1)+c(b-\lambda)]^{2}\right) /\left(8 b(1+2 \alpha)^{2}\right)\right)<0$ and $\left(\partial \prod_{m}^{*} /\right.$ $\partial \theta)=\left(\left(a^{2}[\alpha \theta(5 b-3 \lambda)-\alpha(b-3 \lambda)+\theta(3 b-\lambda)-(b-\lambda)]-\right.\right.$ $\left.\left.a c(3 \alpha+1)\left(b-\lambda^{2}\right)\right) /(4 b(1+\alpha)(b+\lambda))\right)>0$ can be obtained when (18) is used to get the derivation of $\alpha$ and $\theta$. Calculating with $(25), \quad\left(\partial \prod_{m}^{* *} / \partial \alpha\right)=-\left(\left([a(\theta-1)+c(b-\lambda)]^{2}\right) / \quad(8 b\right.$ $\left.\left.(1+2 \alpha)^{2}\right)\right)<0$ and $\left(\partial \prod_{m}^{* *} / \partial \theta\right)=\left(\left(a^{2}[\theta(3 b-\lambda)+2 \alpha \lambda+\right.\right.$ $\left.(b-\lambda)(2 \alpha \theta-1)]-a c(2 \alpha+1)\left(b^{2}-\lambda^{2}\right)\right) /(4 b(1+\alpha) \quad(b+$ $\lambda)))>0$.

Lemma 7 shows that whether the manufacturer considers the retailer's fairness preference or not, the manufacturer's profit will be lower than the case when the retailer has no fairness preference. When the manufacturer thinks over the retailer's fairness preference, he will reduce his profit to add the retailer's profit, thus ensuring the fairness of channel profit distribution. Moreover, the manufacturer's profit when he considers the retailer's fairness preference is higher than that when he ignores it. When the manufacturer ignores the retailer's fairness preference, this may enlarge the retailer's fairness concerns and lead to broader damage. This means that if the retailer has a fairness preference, the manufacturer should consider this behavior more favorable. 


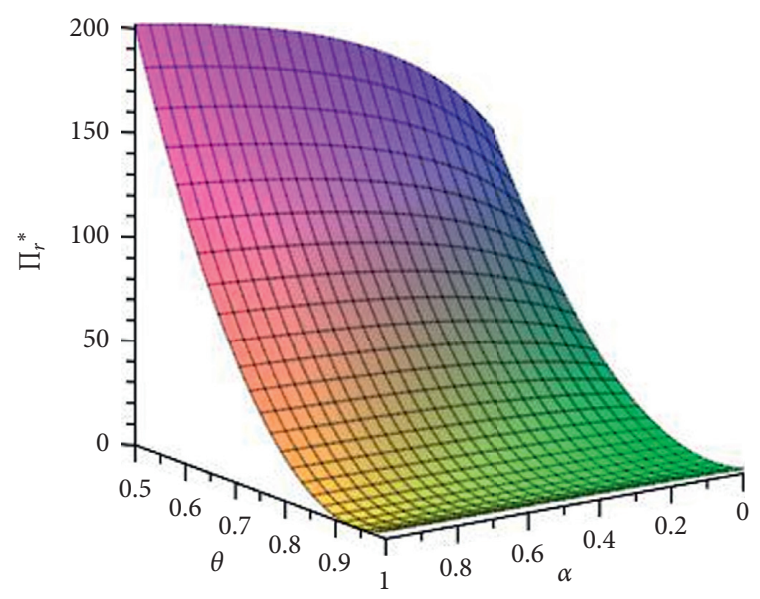

Figure 4: The influence of $\alpha$ and $\theta$ on $\prod_{r}^{*}$.

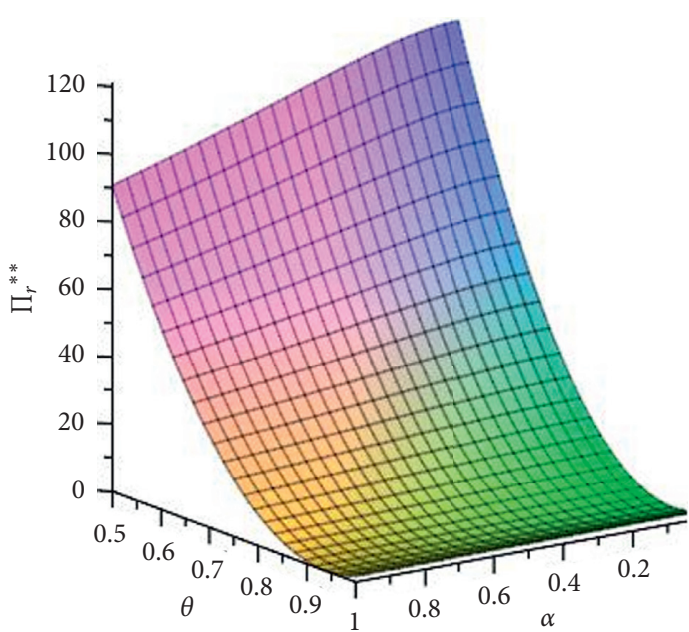

Figure 5: The influence of $\alpha$ and $\theta$ on $\prod_{r}^{* *}$.

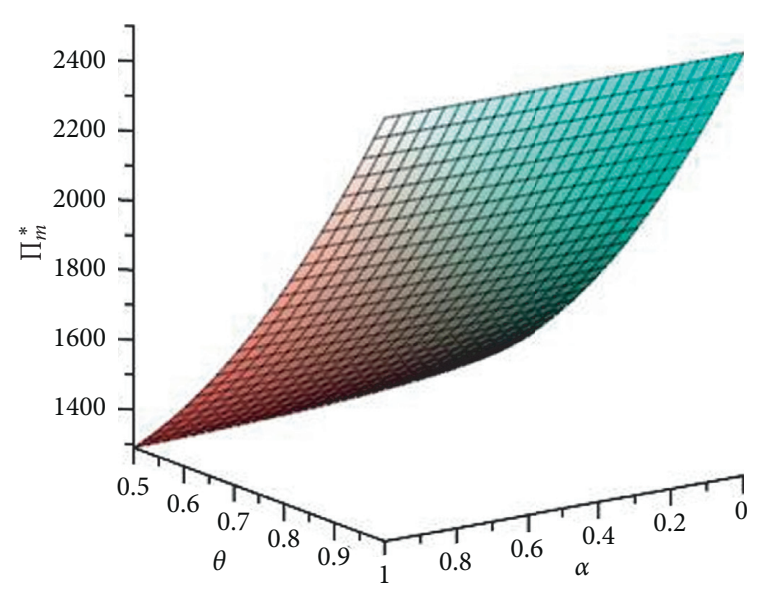

FIgURE 6: The influence of $\alpha$ and $\theta$ on $\prod_{m}^{*}$.

Taking the increase of consumer's online channel preference into account would benefit the manufacturer's profit for both cases. However, the manufacturer's profit that increased by the online channel is smaller than the profit

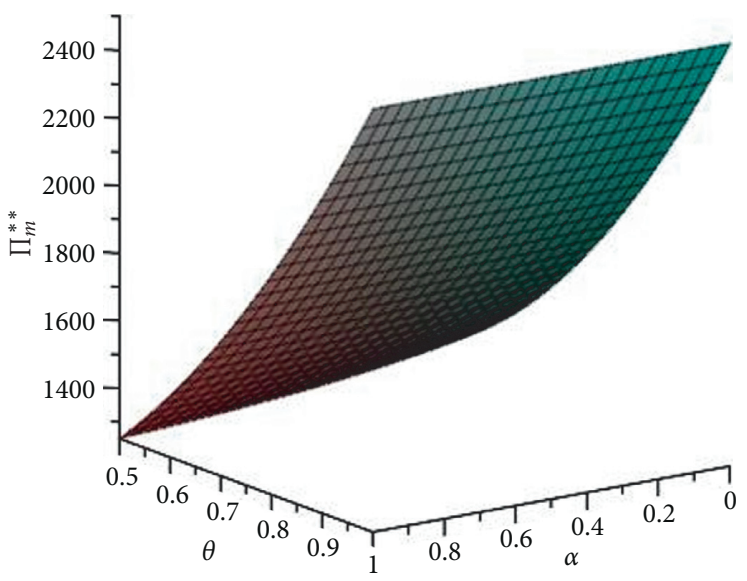

Figure 7: The influence of $\alpha$ and $\theta$ on $\prod_{m}^{* *}$.

transfer for the retailer's fairness preference. When more consumers intend to shop online, this injures the retailer's profit and magnifies her fairness requirements. To ensure the channel operation, the manufacturer can only choose to give the retailer more incentives.

To visually show the analysis in Lemma 7 , the paper applies a numerical example. As shown in Figures 6 and 7, it can be seen that whether the manufacturer considers the retailer's fairness concern or not, the manufacturer's profit will reduce with the increase of $\alpha$ but improve with the increase of $\theta$. The main reason is that the enhancement of fairness preference makes the manufacturer have to give up profit; otherwise, it is difficult to carry out dual-channel cooperation. On the contrary, enhancing consumers' online acceptance enables the manufacturer to obtain more profit from an online channel, leading to an increased profit in the whole dual channels.

\section{Conclusions}

This paper first attempts to study the compound impact of the retailer's fairness preference and consumer's online channel preference on supply chain enterprises' operational strategy. A single manufacturer sells his products by online and offline channels with a retailer in the dual-channel supply chain. To observe supply chain enterprises' operational decisions, this paper uses three circumstances. The benchmark one is that the retailer has no fairness preference, while the manufacturer considers or ignores the retailer's fairness preference as comparative cases. The study shows that the manufacturer intends to build an online channel with lower consumer acceptance when the manufacturer takes the retailer's fairness preference into account. The wholesale price and manufacturer's profit are lower than those in the benchmark case, while the increase in consumer's online channel preference can narrow the gap. The retailer's profit is higher than that without fairness preference because of the manufacturer's interest concession. When the manufacturer ignores the retailer's fairness preference, the retailer will increase offline channel pricing, which hurts the manufacturer's and the retailer's profits, 
although the increase of consumer's online channel acceptance benefits the manufacturer. These results demonstrate that the manufacturer needs to take fairness preference into account to avoid a "lose-lose" situation when the retailer possesses a fairness preference. If the acceptance degree of the online channel is high to a certain extent, the manufacturer needs to provide additional revenue for the retailer to ensure the operation of the dual-channel strategy. For the retailer, her fairness preference needs to be maintained at an appropriate level; otherwise, the manufacturer will start online channel construction earlier, which will affect his profit level.

This paper focuses on the retailer's fairness preference, but, in practical operation, all decision-makers may possess fairness preferences, and the fairness preference could be extended to a more elaborate setting. The market demand is determined to be a linear demand in the study. However, the market demand is random and uncertain or changes to dynamic, which also deserves further study.

\section{Data Availability}

The data used to support the findings of this study are available from the corresponding author upon request.

\section{Conflicts of Interest}

The authors declare that they have no conflicts of interest.

\section{Acknowledgments}

This work was supported by the National Natural Science Foundation of China under Grant 72071065.

\section{References}

[1] W.-Y. K. Chiang, D. Chhajed, and J. D. Hess, "Direct marketing, indirect profits: a strategic analysis of dual-channel supply-chain design," Management Science, vol. 49, no. 1, pp. 1-20, 2003.

[2] H. Xu, Z. Z. Liu, and S. H. Zhang, "A strategic analysis of dualchannel supply chain design with price and delivery lead time considerations," International Journal of Production Economics, vol. 139, no. 2, pp. 654-663, 2012.

[3] P. Zhang, Y. He, and C. Shi, "Retailer's channel structure choice: online channel, offline channel, or dual channels?" International Journal of Production Economics, vol. 191, pp. 37-50, 2017.

[4] J. Guo, B. Cao, W. Xie, Y. Zhong, and Y.-W. Zhou, "Impacts of pre-sales service and delivery lead time on dual-channel supply chain design," Computers \& Industrial Engineering, vol. 147, Article ID 106579, 2020.

[5] B. Zhu, B. Wen, S. Ji, and R. Qiu, "Coordinating a dualchannel supply chain with conditional value-at-risk under uncertainties of yield and demand," Computers \& Industrial Engineering, vol. 139, Article ID 106181, 2020.

[6] J. Chen, Y.-W. Zhou, and Y. Zhong, "A pricing/ordering model for a dyadic supply chain with buyback guarantee financing and fairness concerns," International Journal of Production Research, vol. 55, no. 18, pp. 5287-5304, 2017.
[7] H. T. Cui, J. S. Raju, and Z. J. Zhang, "Fairness and channel coordination," Management Science, vol. 53, no. 8, pp. 1303-1314, 2007.

[8] Z. Guan, T. Ye, and R. Yin, "Channel coordination under Nash bargaining fairness concerns in differential games of goodwill accumulation," European Journal of Operational Research, vol. 285, no. 3, pp. 916-930, 2020.

[9] B. Niu, Q. Cui, and J. Zhang, "Impact of channel power and fairness concern on supplier's market entry decision," Journal of the Operational Research Society, vol. 68, no. 12, pp. 1570-1581, 2017.

[10] K. Pan, Z. Cui, A. Xing, and Q. Lu, "Impact of fairness concern on retailer-dominated supply chain," Computers \& Industrial Engineering, vol. 139, Article ID 106209, 2020.

[11] G. Cai, "Channel selection and coordination in dual-channel supply chains," Journal of Retailing, vol. 86, no. 1, pp. 22-36, 2010.

[12] E. Cao, "Coordination of dual-channel supply chains under demand disruptions management decisions," International Journal of Production Research, vol. 52, no. 23, pp. 7114-7131, 2014.

[13] A. Dumrongsiri, M. Fan, A. Jain, and K. Moinzadeh, "A supply chain model with direct and retail channels," European Journal of Operational Research, vol. 187, no. 3, pp. 691-718, 2008.

[14] B. Dan, G. Xu, and C. Liu, "Pricing policies in a dual-channel supply chain with retail services," International Journal of Production Economics, vol. 139, no. 1, pp. 312-320, 2012.

[15] J. Gao, X. Wang, Q. Yang, and Q. Zhong, "Pricing decisions of a dual-channel closed-loop supply chain under uncertain demand of indirect channel," Mathematical Problems in Engineering, vol. 2016, Article ID 6053510, 13 pages, 2016.

[16] G. Hua, S. Wang, and T. C. E. Cheng, "Price and lead time decisions in dual-channel supply chains," European Journal of Operational Research, vol. 205, no. 1, pp. 113-126, 2010.

[17] W. Huang and J. M. Swaminathan, "Introduction of a second channel: implications for pricing and profits," European Journal of Operational Research, vol. 194, no. 1, pp. 258-279, 2009.

[18] G. Li, F. Huang, T. C. E. Cheng, and P. Ji, "Competition between manufacturer's online customization channel and conventional retailer," IEEE Transactions on Engineering Management, vol. 62, no. 2, pp. 150-157, 2015.

[19] Q. Lu and N. Liu, "Pricing games of mixed conventional and e-commerce distribution channels," Computers \& Industrial Engineering, vol. 64, no. 1, pp. 122-132, 2013.

[20] A. Ranjan and J. K. Jha, "Pricing and coordination strategies of a dual-channel supply chain considering green quality and sales effort," Journal of Cleaner Production, vol. 218, pp. 409-424, 2019.

[21] W. S. Yoo and E. Lee, "Internet channel entry: a strategic analysis of mixed channel structures," Marketing Science, vol. 30, no. 1, pp. 29-41, 2011.

[22] O. Caliskan-Demirag, Y. Chen, and J. Li, "Channel coordination under fairness concerns and nonlinear demand," European Journal of Operational Research, vol. 207, no. 3, pp. 1321-1326, 2010.

[23] S. Du, T. Nie, C. Chu, and Y. Yu, "Newsvendor model for a dyadic supply chain with Nash bargaining fairness concerns," International Journal of Production Research, vol. 52, no. 17, pp. 5070-5085, 2014.

[24] T.-H. Ho, X. Su, and Y. Wu, "Distributional and peer-induced fairness in supply chain contract design," Production and Operations Management, vol. 23, no. 2, pp. 161-175, 2014. 
[25] E. Katok and V. Pavlov, "Fairness in supply chain contracts: a laboratory study," Journal of Operations Management, vol. 31, no. 3, pp. 129-137, 2013.

[26] Q. H. Li and B. Li, "Dual-channel supply chain equilibrium problems regarding retail services and fairness concerns," Applied Mathematical Modelling, vol. 40, no. 15-16, pp. 7349-7367, 2016.

[27] T. Nie and S. Du, "Dual-fairness supply chain with quantity discount contracts," European Journal of Operational Research, vol. 258, no. 2, pp. 491-500, 2017.

[28] S. Du, L. Wei, Y. Zhu, and T. Nie, "Peer-regarding fairness in supply chain," International Journal of Production Research, vol. 56, no. 10, pp. 3384-3396, 2018.

[29] E. Fehr and K. M. Schmidt, "A theory of fairness, competition, and cooperation," The Quarterly Journal of Economics, vol. 114, no. 3, pp. 817-868, 1999.

[30] Z. Qin and J. Yang, "Analysis of a revenue-sharing contract in supply chain management," International Journal of Logistics Research and Applications, vol. 11, no. 1, pp. 17-29, 2008. 